\title{
PERAN BUMDES DALAM PENGUATAN EKONOMI DESA SUKARATU KABUPATEN SERANG, BANTEN
}

\section{THE ROLE OF VILLAGE OWNED ENTERPRISE IN STRENGHTENING THE ECONOMIC OF SUKARATU VILLAGE, SERANG REGENCY, BANTEN PROVINCE}

(disubmit 28 September 2019, direvisi 20 November 2019, diterima 01 Desember 2019)

\author{
Yunia Rahayuningsih ${ }^{1}$, Sofyan Budiarto ${ }^{2}$, Sulastri Isminingsih ${ }^{3}$ \\ ${ }^{1,2}$ Bappeda Provinsi Banten \\ ${ }^{3}$ Universitas Sultran Ageng Tirtayasa \\ KP3B, Jl. Syech Nawawi Al-Bantani, Serang, Banten \\ Email: yuniarahayuningsih@gmail.com
}

\begin{abstract}
ABSTRAK
BUMDes lahir sebagai pendekatan baru dalam usaha peningkatan ekonomi desa berdasarkan kebutuhan dan potensi desa. Desa Sukaratu Kecamatan Cikeusal Kabupaten Serang telah mempunyai BUMDes dan juga memiliki potensi besar dalam sektor pariwisata. Namun sampai saat ini belum tergali dan dikembangkan secara maksimal. Oleh karena itu penelitian ini bertujuan untuk mengetahui peranan BUMDes dalam penguatan ekonomi Desa Sukaratu. Metode yang digunakan dalam penelitian adalah desktiptif kualitatif dengan teknik pengumpulan data melalui wawancara, pengamatan langsung dan pengumpulan data sekunder lainnya. Hasil penelitian menunjukkan bahwa keberadaan BUMDes Ratu Harapan berperan dalam peningkatan kreativitas, inovasi dan variasi usaha BUMDes yang berbasis pada pengelolaan potensi desa di sektor wisata sesuai dengan kebutuhan masyarakat dan peluang pasar. Juga telah mampu berkontribusi terhadap pendapatan asli desa dan membuka lapangan kerja bagi masyarakat desa.
\end{abstract}

Kata Kunci: Badan Usaha Milik Desa, Penguatan Ekonomi, Desa Sukaratu, Kabupaten Serang

\section{ABSTRACT}

Village Owned Enterprise was born as a new approach in efforts to improve the village economy based on the needs and potential of the village. Sukaratu Village, Cikeusal Sub district, Serang District has Village Owned Enterprise and also has great potential in the tourism sector. But until now it has not been fully explored and developed. Therefore, this study aims to determine the role of Village Owned Enterprise in strengthening the economy of Sukaratu Village. The method used in the study is desktiptif qualitative with data collection techniques through interviews, observation and other secondary data collection. The results showed that the existence of the Ratu Harapan's Village Owned Enterprise played a role in increasing creativity, innovation and variations in Village Owned Enterprise business based on managing village potential in the tourism sector in accordance with community needs and market opportunities. It has also been able to contribute to the village's original income and open employment opportunities for the village community. 
Keywords: Village-Owned Enterprise, Economic Strengthening, Sukaratu Village, Serang District

\section{PENDAHULUAN}

Kebijakan otonomi daerah merupakan kebijakan yang memberikan wewenang kepada daerah untuk mengurus dan mengatur kebutuhan masyarakat sesuai dengan karakteristik daerahnya. Oleh karena itu, konsep pembangunan harus lebih diarahkan lagi pada pembangunan berbasis tingkatan terendah dalam suatu struktur pemerintahan, yaitu desa (Goma, 2015: 1). Secara historis, desa merupakan cikal bakal terbentuknya masyarakat politik dan pemerintahan di Indonesia, jauh sebelum negara-bangsa ini terbentuk. Struktur sosial sejenis desa, masyarakat adat, dan lainnya telah menjadi institusi sosial yang sangat penting (Widjaja, 2004: 4). Berkaitan dengan desa, pemerintah telah mengesahkan peraturan yang mengatur khusus tentang pemerintahan desa, yaitu Undang-Undang Nomor 6 Tahun 2014 (UU Desa).

\section{Pertumbuhan ekonomi desa} seringkali dinilai lambat dibandingkan pembangunan ekonomi perkotaan. Untuk meningkatkan hal tesebut dibutuhkan dua pendekatan yaitu: a) Kebutuhan masyarakat dalam melakukan upaya perubahan dan mencegah hal-hal yang tidak diinginkan, dan b) Political will dan kemampuan pemerintah desa bersama masyarakat dalam mengimplementasikan perencanaan pembangunan yang sudah disusun (Rutiadi, 2001 dalam Bachrein, 2010).

Salah satu upaya yang bisa dilakukan adalah dengan mendorong gerak ekonomi desa melalu kewirausahaan desa, dimana kewirausahaan desa menjadi strategi dalam pengembangan dan pertumbuhan kesejahteraan (Ansari, 2016). Kewirausahaan desa ini dapat diwadahi dalam Badan Usaha Milik Desa (BUMDes) yang dikembangkan oleh pemerintah maupun masyarakat desa (Prabowo, 2014).

Desa Sukaratu merupakan salah satu desa yang terletak di Kecamatan Cikeusal, Kabupaten Serang yang memiliki banyak potensi di bidang wisata, baik wisata alam maupun wisata budaya. Jenis-jenis wisata tersebut sangat potensial untuk dikembangkan menjadi obyek wisata unggulan dan daya tarik wisata ke Kabupaten Serang dan apabila dikembangkan secara profesional akan sangat mungkin jika Desa Sukaratu menjadi primadona kunjungan wisatawan baik secara lokal, domestik maupun mancanegara.

Dengan melihat pada potensi 
yang ada dan didukung oleh letak geografis Desa Sukaratu yang strategis dan kondisi alam yang indah sangat memungkinkan pariwisata untuk berkembang pesat. Adapun proses pelaksanaan pengembangan pariwisata sebagai suatu kawasan desa wisata tidak lepas dari peran serta pemerintah dan juga masyarakat lokal yang ikut serta dalam pengembangan desa wisata melalui BUMDes. Selanjutnya, peran serta BUMdes akan sangat memungkinkan untuk penguatan ekonomi desa dan mendorong meningkatkan perekonomian masyarakat setempat. Sebagaimana penelitian yang dilakukan oleh Wibawati (2015: 202) menunjukkan bahwa BUM Desa telah berhasil menjadi lembaga ekonomi pedesaan yang mendukung terwujudnya otonomi desa, mengangkat potensi desa dan mendorong peningkatan kesejahteraan warga masyarakat. Temuan tersebut juga didukung oleh Rahmawati (2014:126) yang juga menunjukkan bahwa keberadaan BUM Desa bermanfaat baik secara sosial maupun ekonomi bagi peningkatan kesejahteraan masyarakat. Berdasarkan fenomena dan hasil penelitian terdahulu tersebut, perlu dilakukan penelitian terkait peran BUMDes dalam penguatan ekonomi Desa Sukaratu, Kabupaten Serang, Banten.

\section{METODE PENELITIAN}

Penelitian dilaksanakan pada bulan Mei - Juli 2019 di Desa Sukaratu, Kecamatan Cikeusal, Kabupaten Serang, Provinsi Banten. Berdasarkan jenis datanya, penelitian ini merupakan penelitian kualitatif sedangkan berdasarkan jenis pemaparannya yaitu bersifat deskriptif. Menurut Sugiyono (2013), metode kualitatif digunakan untuk mendapatkan data yang mendalam, suatu data yang mengandung makna. Kemudian, deskriptif menurut Nugroho (2013) adalah penelitian dengan tujuan mengetahui nilai variabel tanpa membuat pembandingan atau menghubungkan dengan variabel lainnya. Sehingga penelitian ini bermaksud mendeskripsikan fenomena yang terjadi berdasarkan hasil eksplorasi peran BUMDesa dalam penguatan ekonomi desa. Metode ini memungkinkan pendekatan yang lebih luwes, tidak terlalu rinci, tidak lazim mendefinisikan suatu konsep, serta memberi kemungkinan bagi perubahanperubahan manakala ditemukan fakta yang lebih mendasar, menarik, unik, dan bermakna di lapangan. (Aziz dalam Bungin, 2003: 39)

Dalam menggali informasi yang dibutuhkan untuk menjawab pertanyaan penelitian, maka data yang dikumpulkan meliputi data primer dan data sekunder. Data primer diperoleh melalui wawancara dan pengamatan (observasi) terhadap situasi lingkungan dan situasi sosial. 
Sedangkan data sekunder diperoleh dari buku, jurnal penelitian, dan laporan penelitian yang berkaitan dengan penelitian ini. Subjek penelitian ditentukan dengan teknik purposive sampling yang terdiri dari Kepala Desa Sukaratu, Direktur BUMDes Ratu Harapan, pengurus BUMDes Ratu Harapan, dan masyarakat Desa Sukaratu. Selanjutnya, analisis data dilakukan sejak awal pengumpulan data. Teknik analisis data mengacu pada Miles dan Huberman (1992: 16-18) yang mengemukakan bahwa aktivitas dalam analisis data kualitatif dilakukan secara interaktif dan berlangsung secara terus menerus, sehingga datanya sudah jenuh. Aktivitas dalam analisis data yaitu data reduction, data organization, dan interpretation.

\section{HASIL DAN PEMBAHASAN}

Desa Sukaratu terletak di Kecamatan Cikeusal, Kabupaten Serang, Provinsi Banten. Merupakan salah satu desa di Kecamatan Cikeusal dengan luas wilayah $4,23 \mathrm{~km}^{2}$ yang terdiri dari 5 dusun, 5 rukun warga, dan 11 rukun tetangga. Desa Sukaratu telah memiliki Badan Usaha Milik Desa yang bernama BUMDes Ratu Harapan yang berdiri atas dasar program pemerintah dalam upaya membangun dan mensejahterakan masyarakat desa sebagaimana tertuang dalam pasal 1, ayat (6) Undang-Undang Nomor 6 Tahun
2014 yang menjelaskan bahwa Badan Usaha Milik Desa, yang selanjutnya disebut BUM Desa adalah badan usaha yang seluruh atau sebagian besar modalnya dimiliki oleh Desa melalui penyertaan secara langsung yang berasal dari kekayaan Desa yang dipisahkan guna mengelola aset, jasa pelayanan, dan usaha lainnya untuk sebesar-besarnya kesejahteraan masyarakat desa. Meskipun subtansi mengenai BUM Desa bukanlah sesuatu yang baru dalam peraturan tentang pemerintahan desa, BUM Desa sesungguhnya telah diamanatkan dalam Undang-Undang Nomor 32 Tahun 2004 tentang Pemerintahan Daerah (Ridlwan, 2014: 426). Sebagaimana tercantum dalam visi BUM Desa Ratu Harapan, yaitu mewujudkan kesejahteraan masyarakat desa melalui pengembangan usaha ekonomi dan pelayanan sosial. Hal tersebut sesuai dengan pendapat Lemieux (Wahab, 2014:15) yang menyatakan bahwa produk aktivitas-aktivitas yang dimaksudkan untuk memecahkan masalah-masalah publik. Upaya untuk meningkatkan kesejahteraan tersebut dilakukan dengan prinsip dasar BUM Desa, salah satunya yaitu keterpaduan kegiatan BUM Desa yang dikembangkan secara utuh dan menyeluruh sesuai dengan kebutuhan masyarakat dan dilaksanakan dengan mengoptimalkan kerjasama antar masyarakat, pemerintah, pengusaha, Lembaga Swadaya Masyarakat, 
serta pelaku pembangunan lainnya secara sinergis.

BUM Desa Ratu Harapan dibentuk pada tahun 2016 yang pada awalnya bergerak di lini usaha jasa alat pengolahan lahan pertanian, pengembang dan pemasok produk pertanian dan perikanan, namun kemudian memfokuskan pada usaha desa wisata. Kegiatan BUM Desa Ratu Harapan tidak lepas oleh peraturan yang digunakan sebagai dasar pelaksanaan program usaha BUM Desa, sebagaimana pendapat Anderson (Islamy dalam Widodo, 2013:14) menyatakan bahwa kebijakan publik yang bersifat positif selalu berdasarkan peraturan perundangan tertentu yang bersifat memaksa atau otoritatif. Pelaksanaan kegiatan BUM Desa Ratu Harapan merujuk pada peraturan yang berlaku, yaitu Perda Kabupaten Serang Nomor 15 Tahun 2011 Tentang Pedoman Pembentukan BUMDes dan Peraturan Desa Sukaratu Nomor 1 tahun 2016 tentang Pengurusan, Pengelolaan, dan Pembubaran Badan Usaha Milik Desa Ratu Harapan.

Desa Sukaratu mewarisi tradisi dan budaya Banten yang bercorak agraris. Untuk mempromosikan dan melestarikan budaya Banten, Desa Sukaratu bersama BUMDes Ratu Harapan menggagas pembangunan ruang terbuka hijau berupa taman desa yang bernama Taman Mahkota Ratu yang menampilkan konsep ethnic dan agroculture.
Implementasi gagasan pembangunan ruang publik tersebut sempat mengalami kendala karena Desa Sukaratu tidak memiliki tanah desa yang representatif untuk pengembangan taman terbuka hijau. Lalu, pemerintah desa bersama BUMDes Ratu Harapan membujuk warga yang memiliki sawah di hamparan Sukaratu untuk melakukan kerjasama pengembangan wisata bertema agraris. Pembagian keuntungan kerjasama itu terbagi dengan pola $40 \%$ untuk pengurus, $10 \%$ untuk PADes, 27\% untuk BUMDes, 11\% untuk Kas BUMDes, 5\% untuk CSR dan 2-5\% untuk pemilik lahan. Pembangunan taman dimulai pada 2016 dengan pembiayaan dari APBDesa 2016 dan dana swadaya (gotong-royong). Pembangunan Taman Mahkota Ratu mengubah daerah pesawahan yang kotor dan dipenuhi semak-semak menjadi tempat yang menarik dan nyaman. Selanjutnya, BUMDes Ratu Harapan mendapat kewenangan untuk pengelolaan taman desa dengan penyertaan modal dari Dana Desa sejumlah Rp 50.000.000,-

Berkat inovasi itu, Desa Sukaratu dikenal sebagai desa wisata di Kabupaten Serang. Selain itu, dalam perjalanan BUM Desa Ratu Harapan terdapat fenomena positif pelaksanaannya yaitu BUM Desa Ratu Harapan berhasil mengantarkan Desa Sukaratu meraih juara 1 dalam kategori Desa Ketahanan Pangan di Provinsi Banten 
Jurnal Kebijakan Pembangunan Daerah, Vol.3, No.2, Desember 2019, Hal. 80 - 87

p-ISSN: 2597-4971, e-ISSN: 2685-0079

Tahun 2017. Selanjutnya pada Tahun 2018 pendapatan BUMDes Ratu Harapan dari pengelolaan Desa Wisata yaitu sebesar Rp. 128.640.000,- dan menyumbang Rp 16.263.000,- untuk pendapatan asli desa (PADes) serta setiap bulannya BUMD Ratu Harapan mengalokasikan anggaran untuk bantuan sosia//CSR. Namun demikian, beberapa responden menyatakan bahwa kontribusi BUMDes tidak dapat dirasakan langsung oleh masyarakat, keberadaan BUMDes tidak membawa manfaat signifikan bagi peningkatan kesejahteraan warga.

Secara rutin, Taman Mahkota Ratu menjadi ruang untuk; (1) musyawarah kelembagaan desa (PKK, Karang Taruna, RT dan RW); (2) musyawarah terkait pertanian, (3) musyawarah lainnya yang bersifat umum atau insidentil. Pengunjung Taman Mahkota Ratu juga datang dari berbagai daerah, seperti Cilegon, Tangerang, Pandeglang, Lebak, dan juga dari DKI Jakarta. Sebagian besar pengunjung adalah anak-anak muda yang menyukai swafoto (selfie).

Berdasarkan wawancara, kekuatan BUMDes Ratu Harapan adalah sebagai berikut: 1) Pengelola BUMDes memiliki komunikasi yang baik dengan Pemerintah Desa. Komunikasi yang baik ini menunjang kelancaran operasional BUMDes; 2) BUMDes memiliki mekanisme akuntabilitas yang baik dimana BUMDes melaporkan program kerja dan juga hasil usaha secara tertib setiap tahunnya; 3) Dalam setiap pengambilan keputusan, BUMDes menggunakan mekanisme musyawarah yang melibatkan berbagai elemen seperti Pemerintah Desa, BPD, PKK, Karang Taruna, dan tokoh masyarakat. Walaupun menggunakan mekanisme musyawarah, BUMDes merupakan lembaga independen sehingga untuk hal-hal tertentu dapat mengambil keputusan secara mandiri. 4) Adanya kerjasama dan simbiosis yang baik antara pengelola BUMDes dan Pemerintah Desa, saling mendukung dan mempromosikan desa.

\section{Permasalahan yang dihadapi BUMDes}

Berdasarkan hasil penelitian, beberapa permasalahan yang dihadapi oleh BUMDes Ratu Harapan adalah sebagai berikut:

1. Komunikasi. Sebagian besar warga desa sudah mengetahui keberadaan BUMDes Ratu Harapan. Mereka juga mengetahui adanya laporan tahunan yang diberikan oleh pengelola BUMDes, namun mereka mengatakan tidak mengerti secara rinci terkait BUMDes seperti jumlah aset, penghasilan, program kerja, dan sebagainya.Permasalahan muncul dari ketidakpahaman mereka tentang laporan yang diberikan, sebagian lagi 
menyatakan bahwa mereka enggan membaca laporan yang dibuat oleh pengelola. Dari pihak pemerintah desa menuturkan hambatan komunikasi ini juga muncul dari masyarakat yang tidak berani bicara terbuka, hanya bersifat "grenengan".

2. Transparansi dan Akuntabilitas.BUMDes telah memiliki mekanisme pelaporan rutin setiap tahun. Laporan tersebut dibuat tertulis dan diberikan kepada pemangku kepentingan. Permasalahan yang muncul adalah warga tidak mengerti tentang isi laporan, tidak membacanya, atau tidak mengetahui apabila ada laporan tahunan.

Transparansi yang diminta oleh warga selain keuangan adalah transparansi perekrutan karyawan. Masyarakat meminta adanya transparansi proses perekrutan karyawan. Selama ini masyarakat sekitar BUMDes merasa bahwa BUMDes kurang transparan pada proses perekrutan karyawan.

3. Kapasitas Manajerial. Permasalahan dalam kapasitas manajerial terungkap dari pengelola BUMDes serta Pemerintah Desa. Kelemahan utama baik dari BUMDES dan Pemerintah Desa adalah dalam hal administrasi/inventaris dan juga keuangan. Pencatatan yang dilakukan masih sederhana. Hal ini sangat penting terkait dengan nilai aset, omzet, dan juga akuntabilitas. Pengelola juga memerlukan penguatan di bidang pengelolaan SDM dan juga pemasaran. Kemampuan manajemen strategi juga dibutuhkan dalam pengelolaan BUMDes.

\section{KESIMPULAN}

Keberadaan BUMDes
Harapan membawa perubahan yang
signifikan di bidang ekonomi dan juga
sosial. Keberadaan BUMDes berperan
dalam peningkatan kreativitas, inovasi dan
variasi usaha BUMDes yang berbasis pada
pengelolaan potensi desa di sektor wisata
sesuai dengan kebutuhan masyarakat dan
peluang pasar. Juga telah mampu
berkontribusi terhadap pendapatan asli
desa dan membuka lapangan kerja bagi
masyarakat desa.

\section{DAFTAR PUSTAKA}

Ansari, B., et al. (2013). Sustainable Entrepreneurship in Rural Areas. Research Journal of Environmental and Earth Science 5(1): 26-31.

Bachrein, S. (2010). Pendekatan Desa Membangun di Jawa Barat: Strategi Pembangunan dan Kebijakan Pembangunan Perdesaan, Jurnal Analisis Kebijakan Pertanian 8(2): 133-149.

Bungin, B. (2003). Analisis Data penelitian Kualitatif: Pemahaman Filosofis dan Metodologis ke Arah Penguasaan Model Aplikasi 
Cetakan Pertama. Jakarta: PT Raja Grafindo Persada.

Goma, S. (2015). Peran Pemerintah Desa dalam Meningkatkan Pendapatan di Desa Bolangitag Satu Kecamatan Bolang Itang Kabupaten Bolaang Mongondow Utara. Diakses pada 26 Mei 2019, (http://ejournal.unsrat.ac.id/index.p hp/politico/article/download/10055/ 96).

Milles, MB \& Huberman, MA. (1992). Analisa Data Kualitatif. Jakarta: UI Press.

Nugroho, R. (2013). Metode Penelitian Kebijakan. Jakarta: Pustaka Pelajar.

Prabowo, T.H.E. (2014). Developing BUMDes (Village-owned Enterprise) for Sustainable Poverty Alleviation Model Village Community Study in Bleberan-Gunung KidulIndonesia. World Applied Sciences Journal 30 (Innovation Challenges in Multidiciplinary Research \& Practice): 19-26.

Rahmawati. (2014). Peranan Modal Sosial dalam Pengelolaan Badan Usaha Milik Desa (BUM Desa) (Studi di Desa Karangrejek Kecamatan Wonosari dan Desa Bleberan Kecamatan Playen Kabupaten Gunungkidul) [Thesis]. Yogyakarta: Universitas Gadjah Mada.

Ridlwan, Z. (2014). Urgensi Badan Usaha Milik Desa (BUMDes) dalam Pembangun Perekonomian Desa. Jurnal Ilmu Hukum 8 (3): 424-440.

Sugiono. (2013). Metode Penelitian Manajemen, Pendekatan: Kuantitatif, Kualitatif, Kombinasi
(Mixed Methods), Penelitian Tindakan, Penelitian Evaluasi. Bandung: Alfabeta.

Wahab, SA. (2014). Analisis Kebijakan: Dari Formulasi ke Penyusunan Model-Model Implementasi Kebijakan Publik Edisi Kedua. Jakarta: PT. Bumi Aksara.

Wibawati. (2015). Kapasitas Badan Usaha Milik Desa dalam Pengelolaan Potensi Desa (Studi Pada Bumdes Desa Bleberan Kecamatan Playen Kabupaten Gunungkidul Dalam Pengelolaan Potensi Wisata Desa) [Thesis]. Yogyakarta: Universitas Gadjah Mada.

Widjaja, HAW. (2004). Otonomi Desa: Merupakan Otonomi yang Asli, Bulat dan Utuh. Jakarta: PT. RajaGrafindo Persada.

Widodo, J. (2013). Analisis Kebijakan Publik: Konsep dan Aplikasi Analisis Proses Kebijakan Publik Cetakan Sembilan. Malang: Bayumedia Publishing. 